BMJ Open

Diabetes

Research

\& Care

\section{Effect of dose of behavioral weight loss treatment on glycemic control in adults with prediabetes}

\author{
Viviana Bauman, ${ }^{1}$ Aviva H Ariel-Donges, ${ }^{\oplus 1}$ Eliza L Gordon, ${ }^{\circledR 1}$ Michael J Daniels, ${ }^{2}$ \\ Dandan Xu, ${ }^{3}$ Kathryn M Ross, ${ }^{\oplus 1}$ Marian C Limacher, ${ }^{4}$ Michael G Perri ${ }^{1}$
}

To cite: Bauman V, Ariel-Donges AH, Gordon EL, et al. Effect of dose of behavioral weight loss treatment on glycemic control in adults with prediabetes. BMJ Open Diab Res Care 2019;7:e000653. doi:10.1136/ bmjdrc-2019-000653

Received 15 January 2019 Revised 28 April 2019 Accepted 6 May 2019

\section{Check for updates}

\section{(C) Author(s) (or their} employer(s)) 2019. Re-use permitted under CC BY-NC. No commercial re-use. See rights and permissions. Published by BMJ.

\section{${ }^{1}$ Department of Clinical and} Health Psychology, University of Florida, Gainesville, Florida, USA

${ }^{2}$ Department of Statistics, University of Florida, Gainesville, Florida, USA ${ }^{3}$ Department of Statistics and Data Sciences, University of Texas at Austin, Austin, Texas, USA

${ }^{4}$ Department of Medicine, University of Florida, Gainesville, Florida, USA

Correspondence to Dr Michael G Perri; mperri@ufl.edu

\section{ABSTRACT}

Objective This study examined the effects of three doses of behavioral weight loss treatment, compared with a nutrition education control group, on changes in glycemic control in individuals with obesity and prediabetes. Research design and methods The study included 287 adults (77\% female, $81 \%$ White; mean (SD) age $=54.1$ (10.5) years, body mass index $=36.3(3.9) \mathrm{kg} / \mathrm{m}^{2}$, and hemoglobin $\mathrm{A} 1 \mathrm{c}(\mathrm{HbA} 1 \mathrm{c})=5.9(0.2 \%))$. Participants were randomized to one of three behavioral treatment doses (high=24 sessions, moderate $=16$ sessions, or low $=8$ sessions) or to an education group (control=8 sessions). Changes in $\mathrm{HbA1c}$, fasting glucose, and body weight were assessed from baseline to 6 months.

Results Mean $(99.2 \%$ credible interval $(\mathrm{Cl}))$ reductions in $\mathrm{HbA} 1 \mathrm{C}$ were $0.11 \%(0.07 \%$ to $0.16 \%), 0.08 \%(0.03 \%$ to $0.13 \%), 0.03 \%$ ( $-0.01 \%$ to $0.07 \%)$, and $0.02 \%(-0.02 \%$ to $0.07 \%)$, for the high, moderate, low, and control conditions, respectively. Mean $(\mathrm{Cl})$ reductions in fasting blood glucose were $0.26 \mathrm{mmol} / \mathrm{L}$ (0.14 to 0.39 ), $0.09 \mathrm{mmol} / \mathrm{L}$ (0 to $0.19), 0.01 \mathrm{mmol} / \mathrm{L}(-0.07$ to 0.09$)$, and $0.04 \mathrm{mmol} / \mathrm{L}$ $(-0.03$ to 0.12$)$ for the high, moderate, low, and control conditions, respectively. The high-dose treatment produced significantly greater reductions in $\mathrm{HbA} 1 \mathrm{c}$ and fasting blood glucose than the low-dose and control conditions (posterior probabilities $(\mathrm{pp})<0.001)$; no other significant betweengroup differences were observed. Mean $(\mathrm{Cl})$ reductions in body weight were $10.91 \mathrm{~kg}$ (9.30 to 12.64), $10.08 \mathrm{~kg}$ (8.38 to 11.72), $6.35 \mathrm{~kg}$ (5.19 to 7.69), and $3.82 \mathrm{~kg}$ (3.04 to 4.54 ) for the high, moderate, low, and control conditions, respectively. All between-group differences in 6-month weight change were significant (pps<0.001) except for the high-dose versus moderate-dose comparison.

Conclusion For adults with obesity and prediabetes a high dose of behavioral treatment involving 24 sessions over 6 months may be needed to optimize improvements in glycemic control.

Trial registration number NCT00912652.

\section{INTRODUCTION}

Prediabetes, a high-risk condition for the development of type 2 diabetes, affects approximately 84.1 million adults in the USA. ${ }^{1}$ Current estimates predict that without changes in lifestyle or weight loss $11 \%$ of individuals with obesity and prediabetes will progress to type 2 diabetes annually. ${ }^{23}$ Weight

\section{Significance of this study}

What is already known about this subject?

- Weight loss can reduce or prevent the onset of type 2 diabetes, and clinical guidelines recommend a moderate dose (16 weekly sessions) of behavioral weight loss treatment for adults with excess body weight.

What are the new findings?

- A high dose (24 weekly sessions) of behavioral weight loss treatment may be required to optimize improvements in glycemic control among adults with prediabetes.

\section{How might these results change the focus of} research or clinical practice?

- When recommending weight loss for adults with obesity and prediabetes, clinicians should consider prescribing a high dose of behavioral treatment.

reduction in particular is a well-established method for delaying and/or preventing the development of type 2 diabetes in people with prediabetes. ${ }^{4-8} \mathrm{~A}$ variety of weight loss interventions are available for adults with obesity, including behavioral/lifestyle treatment, pharmacotherapy, and bariatric surgery. ${ }^{4-14}$ Behavioral treatment commonly produces mean losses of $8 \%-10 \%$ of initial body weight without the negative side effects or complications associated with pharmacotherapy or surgery. ${ }^{12}$ Guidelines from professional organizations and scientific groups, such as the American Diabetes Association, ${ }^{14}$ the US Preventive Services Task Force, ${ }^{15} 16$ the American College of Cardiology/American Heart Association/The Obesity Society, ${ }^{17}$ and the Centers for Disease Control and Prevention's National Diabetes Prevention Program, ${ }^{18}$ endorse behavioral treatment as the first line of intervention for adults with excess body weight.

Determining an appropriate dose of treatment is a key consideration when prescribing 
behavioral weight loss interventions. ${ }^{19}$ Early studies in this area found that treatment duration was positively associated with weight loss outcomes ${ }^{2021}$; however, more recent work has demonstrated that a 'moderate' dose of treatment may have similar weight outcomes as higher dose treatment. ${ }^{22}$ For example, the Rural Lifestyle Intervention Treatment Effectiveness (Rural LITE) Trial ${ }^{22}$ showed that high (24 weekly sessions) and moderate (16 weekly sessions) doses of behavioral weight loss treatment produced significantly greater weight reductions than low-dose (8 weekly sessions) treatment and a nutrition education control group (8 weekly sessions), but there was no significant difference in the weight losses achieved by the high-dose and moderate-dose conditions.

To our knowledge, no randomized trial has examined the effects of various doses of behavioral weight loss treatment on glycemic control in adults at high risk for developing type 2 diabetes. While there is some evidence to suggest that incremental increases in treatment dose produce larger weight reductions, ${ }^{21} 22$ it is unclear whether the same pattern applies to the effects of treatment dose on glycemic control. Therefore, we conducted secondary data analyses of data from the Rural LITE Trial to evaluate the effect of dose of behavioral weight loss treatment on changes in glycemic control among adults with obesity and elevated hemoglobin A1c (HbAlc) levels.

\section{RESEARCH DESIGN AND METHODS}

\section{Participants}

The current study included 287 of the 612 men and women with obesity who participated in the Rural LITE Trial. ${ }^{22}$ Participants were adults with obesity (age $=21-75$ years old, body mass index (BMI) $\geq 30 \mathrm{~kg} / \mathrm{m}^{2}$ ) who lived in 1 of 10 medically underserved counties in north central Florida and had no medical comorbidities that contraindicated participation in a standard behavioral weight loss program. While the parent trial excluded participants with uncontrolled diabetes, it included participants with well-managed diabetes as well as individuals with normal levels of glycemic control. Full inclusion/exclusion criteria have been published previously. ${ }^{22}$ The current study included only participants with HbAlc levels in the prediabetes range $(\geq 5.7$ and $\leq 6.4 \%)$ who did not have a history of diabetes (per physician diagnosis; see figure 1 for the participant inclusion flow chart). Participants with HbAlc levels in the prediabetes range but who also had a history of diagnosed diabetes were excluded to avoid the possible confounding effect of antihyperglycemic treatment.

\section{Content and doses of treatment}

Eligible participants were randomized to one of the four treatment conditions: high-dose behavioral treatment (HIGH=24 sessions over 6 months), moderate-dose behavioral treatment (MOD=16 sessions over 4 months), low-dose behavioral treatment $(\mathrm{LOW}=8$ sessions over
2 months), or a nutrition education control group (CONTROL $=8$ sessions over 2 months). The number of sessions (8) selected for the LOW and CONTROL conditions reflected the norms in the local community for the delivery of weight loss programs and adult education classes focused on healthy lifestyles. Across all intervention arms and the education control group, treatment was delivered in weekly 90 min group sessions. Groups consisted of 6-15 participants and were led by interventionists with a bachelor's or master's degree in nutrition, exercise science, or psychology (details regarding interventionist training have been published previously).$^{22}$ Intervention content for the HIGH, MOD, and LOW conditions was based on the Diabetes Prevention Program $^{23}$ and was tailored to address concerns unique to residents from rural communities (eg, absence of community exercise facilities, tradition of country cooking). ${ }^{22}$ Participants in the HIGH, MOD, and LOW groups were instructed: (A) to follow a low-calorie diet $(1200 \mathrm{kcal} /$ day for participants weighing $<114 \mathrm{~kg}, 1500 \mathrm{kcal} /$ day for those weighing 114-136 kg, and $1800 \mathrm{kcal} /$ day for those weighing $>136 \mathrm{~kg}$ at baseline); (B) to increase physical activity using a home-based walking program (with a goal of extra $30 \mathrm{~min} /$ day above baseline levels); and (C) to employ behavior change strategies (eg, goal setting, self-monitoring of caloric intake and daily steps, stimulus control, and problem-solving) in order to induce a negative energy balance. While treatment content and written materials were the same for the HIGH, MOD, and LOW conditions, the number of weekly treatment sessions varied according to the dose of treatment. The greater number of sessions in the MOD and HIGH conditions allowed for increased interventionist contact time and greater discussion of content included in the behavioral treatment modules.

The nutrition education condition served as a CONTROL for interventionist attention and for the delivery of relevant weight management information. Each session included a lecture on a topic relevant to nutrition, physical activity, or weight control, followed by a group discussion of how the information was relevant to health and weight management. Participants also received nutrition, physical activity, and health-related educational materials derived from resources available from US government agencies including the National Institutes of Health and the US Department of Agriculture. ${ }^{24} 25$ In contrast to the behavioral treatment groups, participants in the CONTROL condition were not assigned caloric intake or physical activity goals, and they did not receive instruction on behavioral strategies for weight management (eg, goal setting, self-monitoring of caloric intake, and so on).

\section{Measures}

Glycemic control was evaluated via measurements of HbAlc and fasting glucose at baseline and 6 months. Participants were asked to fast for 12 hours prior to having their blood drawn from the arm or hand by a study nurse 


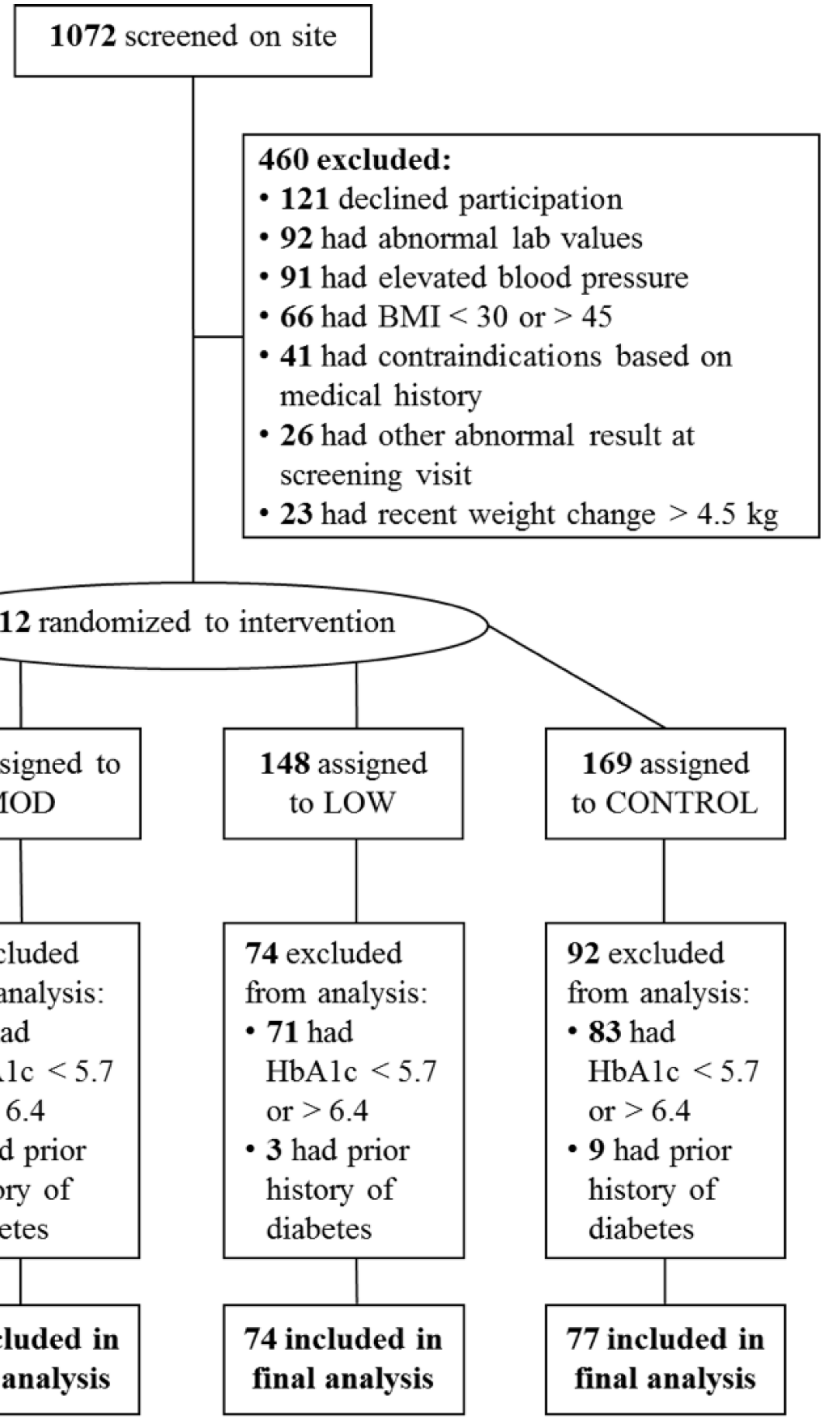

Figure 1 Participant flow through screening, randomization, and data analysis. BMI, body mass index.

masked to treatment conditions. Under aseptic conditions, using standard venipuncture techniques, a $15 \mathrm{ml}$ sample of blood was drawn and subsequently analyzed for glycated hemoglobin and fasting glucose. The samples were analyzed via Immunoturbidimetry by Quest Diagnostics Clinical Laboratories, which is accredited by the College of American Pathologists. Change in glycemic control was calculated by subtracting baseline values from corresponding values at 6 months. Participants were considered to have achieved a clinically significant improvement in glycemic control if $\mathrm{HbAlc}$ decreased by $\geq 0.3 \%$, in accord with the guidelines from Food and Drug Administration $^{26}$ and the European Medicines Agency ${ }^{27}$ regarding diabetes drug development.

Body weight was measured at baseline and 6 months by a study nurse masked to treatment condition. Weight was measured to the nearest $0.1 \mathrm{~kg}$ using a calibrated, certified digital scale (Tanita, Model BWB-800S, Arlington Heights, IL) with participants in light indoor clothing, without shoes. Change in body weight was calculated by subtracting baseline weight from 6 months' weight.
In addition to weight measurements at baseline and 6 months, weekly weight measurements were recorded by interventionists to provide feedback to participants during the program. Weekly weights were used in the missing data analyses, described below, and were measured in the same manner as the baseline and 6 months' weights.

\section{Statistical analyses}

Descriptive statistics were calculated to examine participant characteristics by treatment condition. Testing was carried out to evaluate differences in baseline characteristics, attendance, and 6-month follow-up between treatment groups (using $\chi^{2}$ for categorical variables and one-way analyses of variance for continuous variables). Bayesian non-parametric models, specifically Dirichlet process mixtures ${ }^{28}$ were used to model the distributions of baseline glycemic control and weight, and 6-month changes in glycemic control and weight. Statistical significance was set at the $99.2 \%$ credible interval (CI) excluding the null value (eg, for treatment difference excluding zero), or posterior probabilities (pp) for a difference 
larger than the null and greater than 0.996 . These critical thresholds were based on Bonferroni corrections to the six pairwise comparisons between groups. In the text, we report 95\% CIs for 6-month change for each treatment.

We considered both missing at random (MAR) and missing not at random (MNAR) assumptions for missing data, allowing for the inclusion of sensitivity parameters, which are essential in clinical trials with missing data. ${ }^{28}$ For the MNAR assumption for HbAlc and fasting glucose (measured at baseline and 6 months), the sensitivity parameter corresponds to, on average, HbAlc and fasting glucose returning to baseline after dropout. For weight (measured weekly), the sensitivity parameter depends on the week of dropout and assumes an average weight regain of $0.075 \mathrm{~kg} /$ week $^{3031}$ until reaching baseline. The MAR and MNAR analyses generally revealed the same pattern of significant findings; exceptions are noted in the Results section. All other study outcomes reported in the text, tables, and figures are based on the MNAR analyses.

\section{RESULTS}

\section{Baseline characteristics}

The sample included 287 adults with obesity and prediabetes aged 21.5-76.1 years; the mean (SD) age was 54.1 (10.5) years. Seventy-one participants were randomized to the HIGH condition, 65 to MOD, 74 to LOW, and 77 to CONTROL. At baseline, the mean (SD) for BMI was 36.3 (3.9) $\mathrm{kg} / \mathrm{m}^{2}$, and mean (SD) for HbAlc was $5.9(0.2) \%$ or $41.0(2.2) \mathrm{mmol} / \mathrm{mol}$. The majority of participants were women $(77.4 \%)$. Eighty-one percent of participants self-identified as White, $15.7 \%$ as African-American/ Black, $3.8 \%$ as Hispanic/Latino, and $3.1 \%$ as 'Other' or multiple races. Forty-five percent of participants had a total family income less than $\$ 50000 /$ year. Baseline characteristics and demographics are presented in table 1; there were no significant differences in baseline characteristics by treatment condition.

\section{Attendance and 6-month follow-up}

Overall, participants completed $81.7 \%$ of scheduled treatment sessions. Mean attendance rates for the HIGH, MOD, LOW, and CONTROL conditions were $75.1 \%$, $81.6 \%, 83.6 \%$ and $85.8 \%$, respectively. There was a significant difference in the attendance rates between the HIGH versus CONTROL conditions $(p=0.003)$, but there were no other significant between-group differences. With regard to follow-up at 6 months, $91.6 \%$ of participants returned for assessment. There were no significant differences in the proportion of participants who completed weight measurements by treatment condition. However, there were significant differences between conditions in the percentages of participants who completed blood draws required for measurement of glycemic control. The blood draw completion rate for the MOD condition $(92.3 \%)$ was significantly higher than the rates in the
HIGH, LOW, and CONTROL conditions $(80.3 \%, 68.9 \%$, and $72.7 \%$, respectively; $\mathrm{p}<0.01$ ).

\section{Changes in glycemic control at 6 months}

Estimated within-group changes from baseline to 6 months in the MNAR analysis showed significant improvements in HbAlc and fasting glucose for the HIGH and MOD conditions $(p p s<0.05)$ but not for the LOW and CONTROL groups. Mean (95\% CI) reductions in HbA1c were $0.11 \%(0.07 \%$ to $0.16 \%), 0.08 \%(0.03 \%$ to $0.13 \%)$, $0.03 \%(-0.01 \%$ to $0.07 \%)$, and $0.02 \%(-0.02 \%$ to $0.07 \%)$, for the HIGH, MOD, LOW, and CONTROL conditions, respectively. Of note, the MAR analysis showed a similar pattern but indicated a significant within-group improvement in HbAlc for the LOW condition. Mean (95\% CI) reductions in fasting blood glucose were $0.26 \mathrm{mmol} / \mathrm{L}$ (0.14 to 0.39$), 0.09 \mathrm{mmol} / \mathrm{L}$ (0 to 0.19$), 0.01 \mathrm{mmol} / \mathrm{L}$ ( -0.07 to 0.09$)$, and $0.04 \mathrm{mmol} / \mathrm{L}(-0.03$ to 0.12$)$ for the HIGH, MOD, LOW, and CONTROL conditions, respectively.

With respect to between-group differences at 6 months, the 99.2\% CIs in the MNAR analyses for all measures of glycemic control resulted in intervals excluding zero for HIGH versus LOW and for HIGH versus CONTROL. Of note, the comparison of HIGH versus MOD for fasting glucose was significant $(\mathrm{pp}=0.002)$ in the MAR analysis but not in the MNAR scenario ( $p p>0.05$ ); otherwise, the observed pattern of effects remained significant across both the MAR and MNAR analyses. All other betweengroup comparisons for change in glycemic control were non-significant. Trajectories for changes in HbAlc and fasting glucose are presented in table 2 and figure 2A,B.

In an exploratory analysis, the effect of treatment condition on the achievement of a 'clinically significant' improvement in glycemic control (defined as an HbA1c reduction of $\geq 0.3 \%$ ) was examined. Clinically significant changes were observed in $37.0 \%, 30.3 \%, 18.6 \%$, and $15.5 \%$ of the participants in the HIGH, MOD, LOW, and CONTROL conditions, respectively. The $99.2 \%$ CIs for the differences between the conditions resulted in intervals excluding zero for HIGH versus LOW and for HIGH versus CONTROL; for all other comparisons, the CIs included zero. We also examined the percentage of participants in each condition with HbAlc values less than $5.7 \%$ at month 6 . Based on the MNAR analyses, those values were $29.4 \%, 27.9 \%, 24.1 \%$ and $20.2 \%$, for the HIGH, MOD, LOW, and CONTROL conditions, respectively.

\section{Weight changes at 6 months}

Estimated within-group changes from baseline to 6 months showed significant reductions in body weight for all four conditions $(\mathrm{pp}<0.05)$. The $99.2 \%$ CIs for the differences between the conditions regarding weight loss resulted in intervals excluding zero for the following comparisons: HIGH versus LOW, HIGH versus CONTROL, MOD versus CONTROL, and LOW versus CONTROL; however, the difference between HIGH 
Table 1 Participant baseline characteristics

\begin{tabular}{|c|c|c|c|c|c|}
\hline & HIGH & MOD & LOW & CONTROL & Total \\
\hline Characteristic & $\mathrm{n}=71$ & $\mathrm{n}=65$ & $\mathrm{n}=74$ & $\mathrm{n}=\mathbf{7 7}$ & $\mathrm{n}=\mathbf{2 8 7}$ \\
\hline \multicolumn{6}{|l|}{ Sex, n (\%) } \\
\hline Men & $22(31.0)$ & $14(21.5)$ & 14 (18.9) & $15(19.5)$ & $65(22.6)$ \\
\hline Women & $49(69.0)$ & $51(78.5)$ & $60(81.1)$ & $62(80.5)$ & $222(77.4)$ \\
\hline Age (years), mean (SD) & $55.2(11.1)$ & $54.1(9.9)$ & $53.9(11.6)$ & $53.3(9.0)$ & $54.1(10.5)$ \\
\hline BMI $\left(\mathrm{kg} / \mathrm{m}^{2}\right)$, mean (SD) & $36.4(4.0)$ & $36.3(4.0)$ & $36.0(4.0)$ & $36.4(3.9)$ & $36.3(3.9)$ \\
\hline Body weight $(\mathrm{kg})$, mean (SD) & $100.1(0.8)$ & $100.3(0.8)$ & $100.3(0.6)$ & $101.5(0.4)$ & $100.7(0.6)$ \\
\hline HbA1c (\%), mean (SD) & $5.9(0.2)$ & $5.9(0.2)$ & $5.9(0.2)$ & $5.9(0.2)$ & $5.9(0.2)$ \\
\hline $\mathrm{HbA1c}(\mathrm{mmol} / \mathrm{mol})$, mean (SD) & $41.4(2.2)$ & $41.3(2.2)$ & $41.0(2.2)$ & $41.4(2.2)$ & $41.0(2.2)$ \\
\hline Fasting glucose/mmol/L, mean (SD) & $5.3(0.5)$ & $5.3(0.5)$ & $5.2(0.5)$ & $5.4(0.5)$ & $5.3(0.5)$ \\
\hline \multicolumn{6}{|l|}{ Ethnicity, n (\%) } \\
\hline Hispanic/Latino & $3(4.2)$ & $3(4.6)$ & $2(2.7)$ & $3(3.9)$ & $11(3.8)$ \\
\hline \multicolumn{6}{|l|}{ Race, n (\%) } \\
\hline White & $57(80.3)$ & $58(89.2)$ & $58(78.4)$ & $60(77.9)$ & $233(81.2)$ \\
\hline African-American/Black & $10(14.1)$ & $6(9.2)$ & $14(18.9)$ & $15(19.5)$ & $45(15.7)$ \\
\hline Other/multiple & $4(5.6)$ & $1(1.6)$ & $2(2.7)$ & $2(2.6)$ & $9(3.1)$ \\
\hline \multicolumn{6}{|l|}{ Highest level of education, $\mathrm{n}(\%)$} \\
\hline Less than high school & $2(2.8)$ & $3(4.6)$ & $2(2.7)$ & $2(2.5)$ & $9(3.1)$ \\
\hline High school/GED only & $12(16.9)$ & $12(18.5)$ & $14(18.9)$ & $14(18.2)$ & $52(18.2)$ \\
\hline Vocational or trade school & $10(14.1)$ & $11(16.9)$ & $12(16.2)$ & $9(11.7)$ & $42(14.6)$ \\
\hline Some college or professional school & $23(32.4)$ & $20(30.8)$ & $19(25.7)$ & $26(33.7)$ & $88(30.7)$ \\
\hline Associate's degree & $6(8.5)$ & $9(13.8)$ & $9(12.2)$ & $9(11.7)$ & $33(11.5)$ \\
\hline Bachelor's degree & $13(18.3)$ & $4(6.2)$ & $11(14.8)$ & $8(10.4)$ & $36(12.5)$ \\
\hline Advanced degree & $5(7.0)$ & $6(9.2)$ & $7(9.5)$ & $7(9.1)$ & $25(8.7)$ \\
\hline No response & $0(0.0)$ & $0(0.0)$ & $0(0.0)$ & $2(2.5)$ & $2(0.7)$ \\
\hline \multicolumn{6}{|l|}{ Total annual family income, $\mathrm{n}(\%)$} \\
\hline Less than $\$ 10000$ & $4(5.6)$ & $3(4.6)$ & $1(1.4)$ & $3(3.9)$ & $11(3.8)$ \\
\hline$\$ 10000-\$ 19000$ & $1(1.4)$ & $5(7.7)$ & $5(6.8)$ & $11(14.3)$ & $22(7.7)$ \\
\hline$\$ 20000-\$ 34999$ & $7(9.9)$ & $7(10.8)$ & $18(23.4)$ & $15(19.5)$ & $47(16.4)$ \\
\hline$\$ 35000-\$ 49999$ & $16(22.5)$ & $15(23.1)$ & $8(10.8)$ & $9(11.7)$ & $48(16.7)$ \\
\hline$\$ 50000-\$ 74000$ & $20(28.2)$ & $15(23.1)$ & $20(27.0)$ & $17(22.1)$ & $72(25.1)$ \\
\hline$\$ 75000-\$ 99999$ & $8(11.3)$ & $5(7.7)$ & $9(12.2)$ & $12(15.6)$ & $34(11.8)$ \\
\hline$\$ 100000+$ & $11(15.5)$ & $11(16.9)$ & $9(12.2)$ & $9(11.7)$ & $40(13.9)$ \\
\hline No response & $4(5.6)$ & $4(6.2)$ & $4(5.4)$ & $1(1.3)$ & $13(4.5)$ \\
\hline
\end{tabular}

BMI, body mass index; GED, General Educational Development.

versus MOD was not significant. This pattern of effects was observed under both the MAR and MNAR scenarios. Trajectories for changes in body weight are presented in table 2 and in figure $2 \mathrm{C}$.

\section{DISCUSSION}

Key findings

Identifying the dose of treatment required to optimize improvements in glycemic control represents an important consideration in the prescription of behavioral weight loss interventions for adults with obesity and prediabetes. High and moderate doses of behavioral treatment typically result in greater weight losses than low-dose treatment, but prior to the current study, it remained unclear whether the same pattern of effects would be observed with respect to changes in glycemic control among adults with obesity and prediabetes.

The findings in the current study showed that a high dose of behavioral treatment produced significantly greater reductions in $\mathrm{HbAlc}$ and fasting glucose compared with low-dose treatment and an educational control condition. Notably, a moderate dose of behavioral treatment, which is commonly recommended in guidelines for obesity management, ${ }^{14-18}$ did not produce 
Table 2 Means and 95\% credible intervals for HbA1c, fasting glucose, and body weight at baseline and month 6 by treatment condition

\begin{tabular}{|c|c|c|c|c|}
\hline Measure & $\begin{array}{l}\text { HIGH } \\
n=71\end{array}$ & $\begin{array}{l}\text { MOD } \\
n=65\end{array}$ & $\begin{array}{l}\text { LOW } \\
n=74\end{array}$ & $\begin{array}{l}\text { CONTROL } \\
\mathrm{n}=77\end{array}$ \\
\hline \multicolumn{5}{|l|}{$\mathrm{HbA1c}(\%)$} \\
\hline Baseline & 5.94 (5.90 to 5.97$)$ & 5.93 (5.88 to 5.97$)$ & 5.91 (5.87 to 5.94$)$ & 5.94 (5.91 to 5.98) \\
\hline Month 6 & 5.83 (5.78 to 5.88$)$ & 5.85 (5.79 to 5.91$)$ & 5.88 (5.83 to 5.92$)$ & 5.92 (5.87 to 5.96$)$ \\
\hline \multicolumn{5}{|c|}{$\mathrm{HbA} 1 \mathrm{c}(\mathrm{mmol} / \mathrm{mol})$} \\
\hline Baseline & 41.4 (41.0 to 41.8$)$ & 41.3 (40.8 to 41.8$)$ & 41.0 (40.6 to 41.5$)$ & 41.4 (41.1 to 41.8$)$ \\
\hline Month 6 & 40.2 (29.7 to 40.7 ) & 40.4 (39.8 to 41.1 ) & 40.7 (40.2 to 41.2$)$ & 41.2 (40.7 to 41.7$)$ \\
\hline \multicolumn{5}{|c|}{ Fasting glucose (mmol/L) } \\
\hline Baseline & 5.34 (5.23 to 5.45$)$ & $5.33(5.21$ to 5.44$)$ & 5.20 (5.11 to 5.30$)$ & 5.38 (5.28 to 5.47$)$ \\
\hline Month 6 & 5.07 (4.96 to 5.18 ) & 5.23 (5.12 to 5.33$)$ & 5.19 (5.10 to 5.29$)$ & 5.34 (5.24 to 5.44$)$ \\
\hline \multicolumn{5}{|c|}{ Body weight (kg) } \\
\hline Baseline & $100.09(96.57$ to 103.5$)$ & 100.33 (96.67 to 104.05$)$ & $100.28(97.41$ to 103.49$)$ & 101.51 (98.72 to 104.36$)$ \\
\hline Month 6 & 89.18 (85.82 to 92.25$)$ & 90.25 (86.97 to 93.81 ) & 93.94 (90.87 to 97.23 ) & 97.69 (94.80 to 100.65$)$ \\
\hline
\end{tabular}

significantly greater improvements in glycemic control compared with the low-dose treatment or the nutrition education condition. Furthermore, only the high-dose treatment resulted in a statistically larger percentage of participants who achieved clinically significant reductions in HbAlc compared with the low-dose and the education control condition.

Participants in the high-dose and moderate-dose treatment groups in this study achieved mean reductions in HbAlc of $0.11 \%$ and $0.08 \%$ ( 1.20 and $0.90 \mathrm{mmol} / \mathrm{mol}$ ), respectively. The magnitude of these improvements is similar to the finding from the original Diabetes Prevention Program trial, ${ }^{4}$ which demonstrated a $0.10 \%(1.10$ $\mathrm{mmol} / \mathrm{mol}$ ) reduction in $\mathrm{HbAlc}$ over 6 months and subsequently a $58 \%$ reduction in diabetes incidence over 3 years for individuals randomized to behavioral weight loss treatment. In the current study, the MNAR analysis revealed no significant differences between the high-dose and moderate-dose conditions with respect to changes in weight or HbAlc. However, in the MAR analysis, the high-dose treatment showed a significantly greater improvement in fasting glucose compared with the moderate-dose condition. In both the MAR and MNAR analyses, only the high-dose treatment achieved significant improvements in both weight and glycemic control compared with low-dose treatment and the education control group.

The results from the current study also showed that high and moderate doses of behavioral treatment produced similar degrees of weight reduction in adults with obesity and prediabetes. Furthermore, the weight losses experienced by participants who received the high and moderate doses were significantly greater than those experienced by participants randomized to the low dose or nutrition education control (both eight sessions). These findings mirror the pattern of effects observed in the parent Rural LITE Trial, ${ }^{22}$ which included adults with normal glycemic levels and with type 2 diabetes as well as individuals with prediabetes.

The findings from the current study argue for standardization in how dose of behavioral treatment is defined and recommended. A common definition of optimal treatment dose will aid in the communication of appropriate prescriptions for behavioral treatment. Moreover, treatment recommendations should take into account whether the target outcome is weight loss alone or weight loss with improved glycemic control. With respect to weight change, moderate-dose and high-dose treatments appear to produce equivalent weight reductions. ${ }^{22}$ However, the findings from the current study showed that only the high-dose treatment produced statistically and clinically significantly greater improvement in glycemic control compared with the low-dose and nutrition education conditions. The longer length of treatment in the high-dose treatment (24 weeks) versus the low-dose and control conditions (each 8 weeks), coupled with greater weight loss, may account for the greater improvements in glycemic control observed in the high-dose treatment compared with the low-dose and control conditions.

\section{Strengths and limitations}

To our knowledge, this study is the first randomized controlled trial to examine the effect of dose of behavioral treatment on changes in both weight and glycemic control as assessed by HbA1c and fasting glucose values. Other strengths of the current study include the recruitment of a large sample of adults with obesity and prediabetes, the implementation of behavioral treatment in medically underserved community settings, the use of Bayesian non-parametric modeling, and the incorporation of both MAR and MNAR analyses to account for the potential influence of missing data.

This study has several limitations. First, although we incorporated a nutrition education control condition, 
A

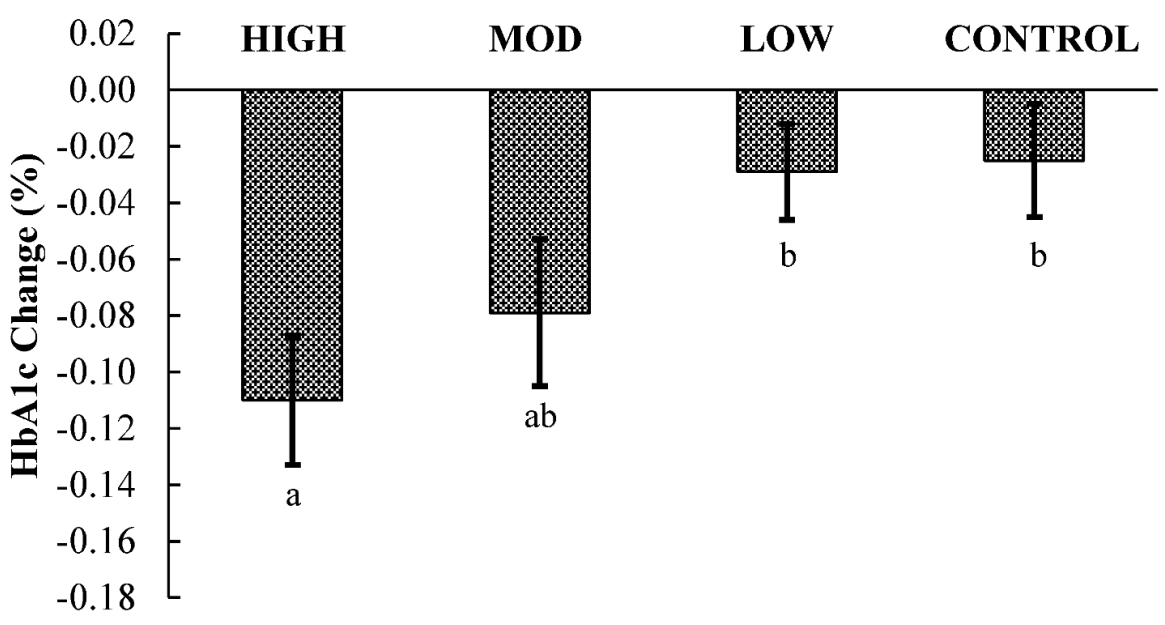

B

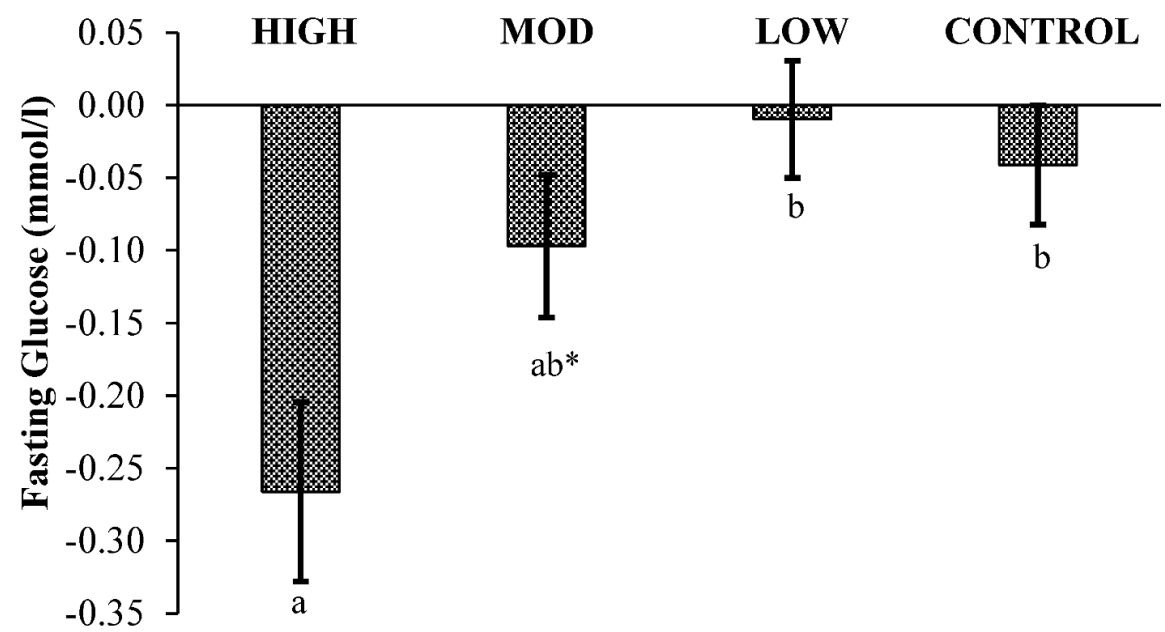

$\mathbf{C}$

HIGH MOD LOW CONTROL

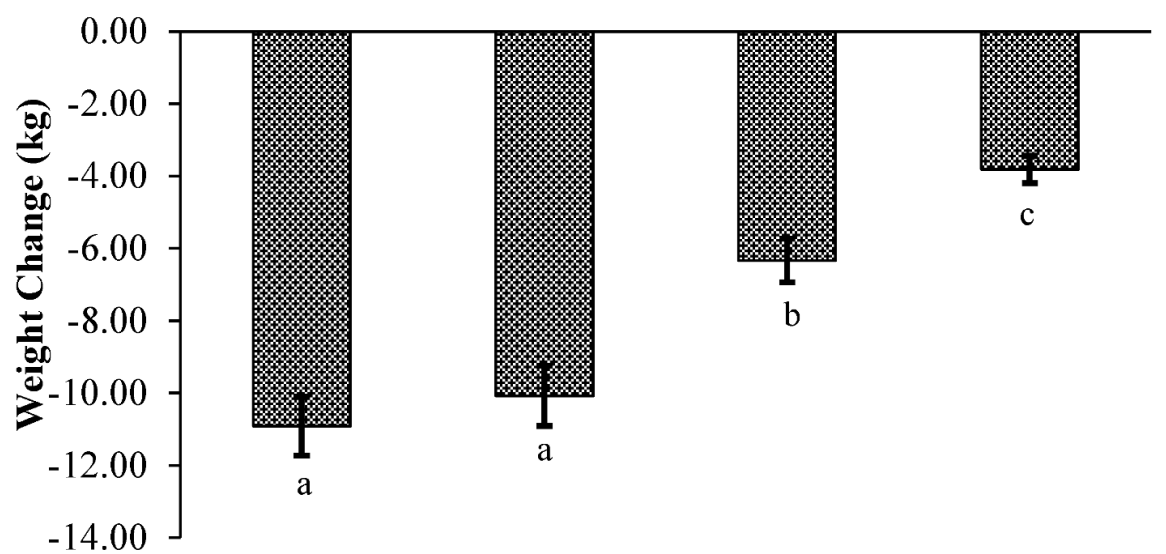

Figure 2 Changes (means \pm posterior SDs) in $\mathrm{HbA1c}(\mathrm{A})$, fasting glucose (B), and body weight (C) by treatment condition based on missing not at random (MNAR) analyses. Means that do not share subscript letters differ significantly from each other. *NOTE: The HIGH versus MOD difference in fasting glucose was significant in the missing at random (MAR) analysis $(\mathrm{pp}=0.002)$.

our design did not include an untreated control group. Participants in the nutrition education condition achieved a mean weight loss of $3.82 \mathrm{~kg}$ and a mean reduction in $\mathrm{HbAlc}$ of $0.02 \%(0.20 \mathrm{mmol} / \mathrm{mol})$. It is unlikely that an untreated group of individuals with obesity and prediabetes would achieve comparable improvements in weight and glycemic control. ${ }^{31}{ }^{32}$ Second, following the start of treatment, change in HbAlc was measured 
at only one time point (ie, 6 months). More frequent measurements (eg, 2 and 4 months) would have enabled a determination of the degree of glycemic change that occurred immediately following the completion of the control and low-dose treatments, which concluded after 2 months, and immediately following the moderate-dose treatment, which concluded after 4 months. During the interval between the completion of treatment for these conditions and the 6-month assessment, participants in the moderate, low, and control groups may have begun to regain weight. Because HbAlc measurement provides an estimate of average blood sugars over the preceding period of 3-4 months, ${ }^{33}$ it is possible that the immediate post-treatment improvements in glycemic control for participants in these conditions may not have been captured at the 6-month assessment. Third, changes in diet composition and physical activity were not available for inclusion as covariates in our analyses. However, findings from the Diabetes Prevention Program showed that weight loss, rather than changes in diet composition or physical activity, was the single factor mostly closely associated with improved glycemic control. ${ }^{34}$ Fourth, an assessment of long-term changes in glycemic control was not available; consequently, the maintenance of changes in HbAlc and fasting glucose is unknown. Finally, the study sample comprised largely White women from rural communities in Florida; the generalizability of the findings to other populations may be limited.

\section{CONCLUSIONS}

Practice guidelines for the management of obesity ${ }^{14-18}$ commonly recommend a moderate dose of behavioral treatment. Moreover, while clinical trials have demonstrated the beneficial effects of moderate-dose ${ }^{4}$ and high-dose $^{35}$ interventions, low-dose treatment often continues to be the norm in many clinical and community settings. ${ }^{36}{ }^{37}$ The findings in the present investigation indicate the need for further study of the short and long-term effects of various treatment doses on glycemic control. If replicated, the results of the current study would suggest that for adults with obesity and prediabetes a high dose of behavioral weight loss treatment may be needed to produce clinically meaningful improvements in glycemic control.

Contributors All authors participated in this research. MGP designed the parent study. MGP and VB jointly designed the current study. VB completed the literature searches and drafted the manuscript. DX and MJD performed the statistical analyses. MGP, KMR, AHAD, ELG, DX, MJD, and MCL edited the text, tables, and figures, and approved the final version of the manuscript.

Funding Funding was provided by the National Heart, Lung, and Blood Institute (NHLBI, R01HL87800) and the National Cancer Institute (NCl, R01CA183854). $\mathrm{NHLBI}$ and $\mathrm{NCl}$ had no role in the study design, collection, analysis, or interpretation of the data, writing the manuscript, or the decision to submit the paper for publication.

Competing interests None declared. DX participated in the study while working at the University of Texas at Austin, prior to her current affiliation with the US Food and Drug Administration (FDA). Thus, study findings and conclusions were not formally disseminated by the FDA and should not be construed to represent an agency decision or policy.

Provenance and peer review Not commissioned; externally peer reviewed.

Data sharing statement All data relevant to the study are included in the article or uploaded as supplementary information.

Open access This is an Open Access article distributed in accordance with the Creative Commons Attribution Non Commercial (CC BY-NC 4.0) license, which permits others to distribute, remix, adapt, build upon this work non-commercially, and license their derivative works on different terms, provided the original work is properly cited and the use is non-commercial. See: http://creativecommons.org/ licenses/by-nc/4.0/

\section{REFERENCES}

1. Centers for Disease Control and Prevention. National diabetes statistics report, 2017. Available: https://www.cdc.gov/diabetes/ data/statistics/statistics-report.html [Accessed 3 April 2019].

2. Tabák AG, Herder C, Rathmann W, et al. Prediabetes: a high-risk state for developing diabetes. Lancet 2012;379:2279-90.

3. Centers for Disease Control and Prevention (CDC). Awareness of prediabetes-United States, 2005-2010. MMWR Morb Mortal Wkly Rep 2013;62:209-12.

4. Knowler WC, Barrett-Connor E, Fowler SE, et al. Reduction in the incidence of type 2 diabetes with lifestyle intervention or metformin. N Engl J Med 2002;346:393-403.

5. Resnick H, Valsania P, Halter J, et al. Relation of weight gain and weight loss on subsequent diabetes risk in overweight adults. $J$ Epidemiol Community Health 2000;54:596-602.

6. Liebermeister $\mathrm{H}$. Effects of weight-reduction on obesity-associated diseases. Ger Med Sci 2003:1.

7. Patel YR, Kirkman MS, Considine RV, et al. Changes in weight and glucose can protect against progression in early diabetes independent of improvements in $\beta$-cell function. The Journal of Clinical Endocrinology \& Metabolism 2016;101:4076-84.

8. Unick JL, Beavers D, Bond DS, et al. The long-term effectiveness of a lifestyle intervention in severely obese individuals. The American Journal of Medicine 2013;126:236-42.

9. Eckel RH, Kahn SE, Ferrannini E, et al. Obesity and type 2 diabetes: what can be unified and what needs to be individualized? The Journal of Clinical Endocrinology \& Metabolism 2011;96:1654-63.

10. Bray GA. Medical consequences of obesity. The Journal of Clinical Endocrinology \& Metabolism 2004;89:2583-9.

11. Breeze PR, Thomas $\mathrm{C}$, Squires $\mathrm{H}$, et al. The impact of type 2 diabetes prevention programmes based on risk-identification and lifestyle intervention intensity strategies: a cost-effectiveness analysis. Diabet. Med. 2017;34:632-40.

12. Stanford J, Kaiser M, Ablah E, et al. The effect of weight loss on fasting blood sugars and hemoglobin A1c in overweight and obese diabetics and non-diabetics. JDM 2012;02:126-30.

13. Butryn ML, Webb V, Wadden TA. Behavioral treatment of obesity. Psychiatric Clinics of North America 2011:34:841-59.

14. American Diabetes Association. Introduction: standards of medical care in diabetes-2018. Diabetes Care 2018;41(Suppl 1):S1-S2.

15. McTigue KM, Harris R, Hemphill B, et al. Screening and interventions for obesity in adults: summary of the evidence for the U.S. Preventive Services Task Force. Ann Intern Med 2003;139:933-49.

16. US Preventive Services Task Force. Behavioral weight loss interventions to prevent obesity-related morbidity and mortality in adults: US Preventive Services Task Force recommendation statement. JAMA 2018;320:1163-71.

17. Jensen MD, Ryan DH, Apovian CM, et al. 2013 AHA/ACC/TOS guideline for the management of overweight and obesity in adults: a report of the American College of Cardiology/American Heart Association Task Force on practice guidelines and the obesity Society. J Am Coll Cardiol 2014;63:2985-3023.

18. Albright $A$. The national diabetes prevention program: from research to reality. Diabetes Care Educ News/ 2012;33:4-7.

19. Voils $\mathrm{Cl}$, King HA, Maciejewski ML, et al. Approaches for informing optimal dose of behavioral interventions. Ann Behav Med 2014;48:392-401.

20. Bennett GA. Behavior therapy for obesity: a quantitative review of the effects of selected treatment characteristics on outcome. Behavior Therapy 1986;17:554-62.

21. Perri MG, Nezu AM, Patti ET, et al. Effect of length of treatment on weight loss. Journal of Consulting and Clinical Psychology 1989;57:450-2.

22. Perri MG, Limacher MC, von Castel-Roberts $\mathrm{K}$, et al. Comparative effectiveness of three doses of weight-loss counseling: two-year findings from the Rural LITE trial. Obesity 2014;22:2293-300. 
23. The Diabetes Prevention Program Research Group. The Diabetes Prevention Program (DPP): description of lifestyle intervention. Diabetes Care 2002;25:2165-71.

24. National Institute of Diabetes and Digestive and Kidney Diseases. Understanding Adult Overweight \& Obesity. Available https:// www.niddk.nih.gov/health-information/weight-management/adultoverweight-obesity (Accessed 3 April 2019)

25. United States Department of Agriculture. Choose MyPlate: 10 tips to a great plate, 2016. Available: https://www.choosemyplate.gov/tentips-choose-myplate [Accessed 3 April 2019].

26. Food and Drug Administration. Guidance for industry diabetes mellitus: developing drugs and therapeutic biologics for treatment and prevention - draft guidance, 2008. Available: https://www.fda. gov/media/71289/download [Accessed 15 March 2019].

27. Committee for Medicinal Products for Human Use, European Medicines Agency. Guideline on clinical investigation of medicinal products in the treatment or prevention of diabetes mellitus, 2012. Available: https://www.ema.europa.eu/en/documents/scientificguideline/guideline-clinical-investigation-medicinal-productstreatment-prevention-diabetes-mellitus-revision_en.pdf [Accessed 15 March 2019].

28. Escobar MD, West M. Bayesian density estimation and inference using mixtures. Journal of the American Statistical Association 1995;90:577-88.

29. Daniels MJ, Hogan JW. Missing data in longitudinal studies: strategies for Bayesian modeling and sensitivity analysis. Boca Raton, FL: CRC Press, 2008.
30. National Research Council (US) Panel on Handling Missing Data in Clinical Trials. The prevention and treatment of missing data in clinical trials. Washington, DC: National Academies Press, 2010.

31. Jeffery RW, Epstein LH, Wilson GT, et al. Long-term maintenance of weight loss: current status. Health Psychology 2000;19(1, Suppl):5-16.

32. Wadden TA, Berkowitz RI, Womble LG, et al. Randomized trial of lifestyle modification and pharmacotherapy for obesity. $N$ Engl $J$ Med 2005;353:2111-20.

33. Little RR, Sacks DB. HbA1c: how do we measure it and what does it mean? Current Opinion in Endocrinology, Diabetes and Obesity 2009;16:113-8

34. Hamman RF, Wing RR, Edelstein SL, et al. Effect of weight loss with lifestyle intervention on risk of diabetes. Diabetes Care 2006;29:2102-7.

35. The Look AHEAD Research Group. Eight-year weight losses with an intensive lifestyle intervention: the Look AHEAD study. Obesity 2014;22:5-13.

36. Kim KH-cheon, Linnan L, Kramish Campbell M, Kim KH, Campbell $\mathrm{MK}$, et al. The word (wholeness, oneness, righteousness, deliverance): a faith-based weight-loss program utilizing a community-based participatory research approach. Health Educ Behav 2008;35:634-50.

37. Parker VG, Coles C, Logan BN, et al. The LIFE project: a community-based weight loss intervention program for rural African American women. Fam Community Health 2010;33:133-43. 